QUADERNS DE FILOSOFIA VOL. VI NÚM. 2 (2019): I 3 I-4I

eISSN: 234I-3042 DOI: I0.7203/QFIA. 6.2.I6056

Óscar Cubo

Universitat de València

\title{
Los límites exteriores del capitalismo en la "crítica de la economía política" de Marx. Sobre la interpretación de César Ruiz Sanjuán de la articulación de historia y sistema en Marx
}

The Outer Limits of Capitalism in Marx's "Critique of Political Economy». On César Ruiz Sanjuán's Interpretation of the Articulation of History and System in Marx.

Recibido: / Aceptado:

Resumen: Se ha publicado recientemente en castellano una investigación rigurosa y pionera acerca de la compleja articulación que mantienen la historia y la exposición del sistema capitalista en el proyecto de una "crítica de la economía política" de Marx. Este trabajo pretende exponer y discutir las aportaciones interpretativas abiertas por el libro de César Ruiz Sanjuán: Historia y sistema en Marx. Hacia una teoría crítica del capitalismo, publicado en 2019 en la editorial Siglo XXI España. Al final de nuestra exposición profundizamos en esta articulación entre historia y sistema con vistas a presentar el proyecto político del Marx maduro como un desarrollo consecuente de su "crítica de la economía política".

Abstract: A groundbreaking and rigorous research has recently been published in Spanish on the complex articulation between history and the exposure of capitalist system in Marx's project of a "Critique of Political Economy". This work aims to present and discuss the interpretative contributions opened by César Ruiz Sanjuán's book Historia y sistema en Marx. Hacia una teoría crítica del capitalismo, published in 2019 by Siglo XXI España. At the conclusion of this paper, we delve into this articulation between history and system in order to present 
Marx's mature political project as a consequent development of his "Critique of Political Economy".

Paraules clau: historia, sistema y crítica de la economía política.

Keywords: history, system and critique of political economy.

$\mathrm{T}$ RAS UN ENORME BAgaje EN LA TRADUCCIÓn de la obra de Michael Heinrich al castellano ${ }^{1}$ y en la difusión en el mundo hispanohablante de lo que en Alemania se conoce como la "nueva lectura de Marx", el profesor César Ruiz Sanjuán presenta un detallado trabajo sobre la relación que guardan lo histórico y lo sistemático en la obra de K. Marx. Una de las mayores dificultades a las que se enfrenta Ruiz Sanjuán en su trabajo es el hecho de que el propio Marx en su evolución intelectual "pasa por distintas fases en el proceso de formación de su teoría, lo que exige abordar el conjunto de su obra para comprender cómo se configura dicha articulación en su formulación teórica definitiva” (Ruiz SAnjuán 20 I9, 9). A lo largo de estas fases, Marx mantiene una fructífera discusión con la filosofía especulativa de G. W. F. Hegel que Ruiz Sanjuán reconstruye a lo largo de su libro de una manera detallada y precisa.

El propósito fundamental del libro es, por tanto, reconstruir esta evolución intelectual de Marx, objetivo que se lleva a cabo en dos pasos: el primero, dedicado a la "Génesis de una concepción histórica de la realidad social" (25162) y, el segundo, centrado en "La exposición sistemática como crítica de las categorías" (163-390). En esta última parte del libro es donde se presenta en toda su complejidad la formulación teórica definitiva de Marx acerca del modo como ha de entenderse la relación entre historia y sistema en su proyecto de una crítica de la economía política. La reconstrucción de la evolución teórica de Marx a lo largo de las dos partes del libro es ejemplar por varios motivos, el primero de ellos, por el tratamiento de las fuentes (muy complejas en el caso de la obra de Marx) y, en segundo lugar, por las delimitaciones previas que el autor emprende antes de embarcarse en su compleja tarea. Respecto a la primera cuestión, esto es, respecto al tratamiento de las fuentes, el autor hace uso de primera mano del corpus marxiano proponiendo en numerosas ocasiones traducciones propias, y mantiene una traducción consecuente y bien pensada de los conceptos fundamentales que Marx emplea a lo largo de toda su obra. Un lector atento puede entrever el enorme trabajo de traducción que Ruiz San-

${ }^{1}$ Véase: Crítica de la economía política. Una introducción a "El Capital" de Marx (2008) y ¿Cómo leer "El Capital" de Marx? Indicaciones de lectura y comentario del comienzo de "El Capital" (20 I I), ambas obras aparecidas en la editorial Escolar y Mayo. 
juán ha realizado en los últimos ańos y la importancia que ello tiene cuando se trabaja sistemáticamente el corpus marxiano, que aún dista mucho de estar completamente traducido al castellano.

En segundo lugar, y por lo que respecta a las delimitaciones previas que Ruiz Sanjuán presenta en la "Introducción", resulta patente que el autor ha sabido hacer suyos uno de los rasgos distintivos de la "nueva lectura de Marx", que consiste en investigar el corpus marxiano con el esmero y cuidado que merecen los autores clásicos de la historia de la filosofía. Con vistas a ello Ruiz Sanjuán emprende una delimitación interna y una delimitación externa del corpus textual que quiere investigar. La primera de estas delimitaciones conlleva una periodización precisa de la obra de Marx que haga posible "separar los elementos teóricos que no encuentran continuidad en la ulterior elaboración de su teoría de aquellos que permanecen y permiten arrojar luz sobre ella" (9). Mientras que la segunda delimitación, esto es, la delimitación externa implica establecer "una línea de demarcación sistemática entre los textos de Marx y los de Engels, lo cual hace posible analizar la relación existente entre ellos y constatar las posibles diferencias que se puedan presentar, en lugar de presuponer que Marx sostiene determinados planteamientos que no se encuentran explícitamente formulados en ningún lugar de su obra e interpretar esta a partir de dichos planteamientos" (10).

Los frutos interpretativos más prominentes de ambas delimitaciones del corpus marxiano, así como del tratamiento directo de las fuentes marxianas, los encontramos especialmente en la segunda parte del libro, donde Ruiz Sanjuán descifra minuciosamente la compleja articulación de lo histórico y sistemático en el proyecto teórico de la crítica de la economía política. Las cuatro versiones disponibles de El Capital constituyen las fuentes primarias del trabajo de Ruiz Sanjuán, aunque también forman parte consustancial de la presente investigación los Grundrisse y el Urtext, ya que en opinión del autor ambos textos permiten completar ciertos vacíos teóricos que se presentan en El Capital. La importancia de los Grundrisse y el Urtext consiste en que permiten localizar ciertas alteraciones en la concepción metodológica de Marx a lo largo de los años posteriores a la redacción de los manuscritos, a pesar de ser el primer volumen de El Capital el verdadero legado intelectual de Marx. "En cuanto a los libros segundo y tercero de El Capital [...] en la medida en que se trata de textos de Marx no acabados y no preparados para su publicación, son escritos del mismo rango que el resto de los manuscritos de la crítica de la economía política" (175). Por todo ello, Ruiz Sanjuán se distancia por igual "de las interpretaciones que consideran que los textos de los que hay que partir son los manuscritos, y de las interpretaciones que sostienen que se debe tomar en consideración exclusivamente El Capital y hay que desechar los manuscritos, e 
incluso la Contribución" (178). Frente a este uso sesgado del corpus marxiano, Ruiz Sanjuán adopta como texto fundamental el primer volumen de El Capital y recurre a la Contribución y a los diversos manuscritos de Marx "para aclarar o para completar la exposición de El Capital en los puntos en que esta sea menos precisa o esté menos desarrollada" (Ibid.).

Pues bien, de este enorme trabajo con las fuentes y del análisis comparativo de los distintos manuscritos, Ruiz Sanjuán extrae importantes resultados por lo que respecta al proyecto teórico del Marx maduro. El primero de ellos, sería lo que podemos denominar la "tesis de la popularización", según la cual Marx fue popularizando progresivamente su exposición de la crítica de la economía política en sus sucesivas versiones, haciendo que "las articulaciones metodológicas [se fueran] quedando cada vez más ocultas” (17). Esta progresiva simplificación de la exposición tuvo una gran importancia en la recepción de la obra de Marx, tanto en el marxismo oriental como en el marxismo occidental, favoreciendo interpretaciones sesgadas y equívocas de su proyecto científico y político. Según Ruiz Sanjuán, esta popularización tuvo lugar por "los sucesivos intentos por parte de Marx de paliar el elevado nivel de abstracción de su exposición del valor y de hacerla más accesible" (184). La consecuencia más negativa de esta popularización fue el progresivo ocultamiento del método que está a la base de la crítica de la economía política y la disolución de los tránsitos dialécticos que enhebran los distintos momentos de la crítica en su conjunto.

Otro resultado que conviene destacar es la "tesis de la centralidad de la teoría del valor", que según Ruiz Sanjuán constituye el concepto clave para exponer y al mismo tiempo criticar el proceso social específico del sistema capitalista. Esta especificidad de la teoría del valor impide igualmente su empleo como una teoría suprahistórica para explicar todas las relaciones de intercambio en general, incluidas las relaciones económicas de las formaciones sociales precapitalistas. Hacer hincapié en la historicidad del proceso de producción específico del sistema capitalista implica igualmente mostrar "el carácter históricamente determinado de las relaciones sociales del modo de producción capitalista" (20).

Posiblemente el resultado más importante de la obra de Ruiz Sanjuán es sacar a la luz el método que hay a la base de la crítica de la economía política. Según el autor, en los Grundrisse encontramos la primera concepción metodológica de Marx como base de su exposición sistemática de las categorías fundamentales de la economía política (167). Este primer borrador de la crítica de la economía política fue elaborado por Marx en 1857, es decir, diez años antes de la publicación de El Capital, y constituye para Ruiz Sanjuán "la base para todas las posteriores versiones de la crítica de la economía política” (171). Un elemento clave de la comprensión de la metodología de Marx es el carácter 
abstracto del punto de partida de la exposición de El Capital. En efecto, "la exposición de El Capital comienza con una construcción conceptual en la cual las relaciones económicas consisten en el intercambio de mercancías y dinero, y el capital no se presenta todavía en ningún momento. Esto no significa que Marx esté analizando sociedades históricas en las que no existe aún el capital, sino que en su exposición de la sociedad capitalista comienza haciendo abstracción del capital. Marx realiza esta abstracción en el primer nivel de su exposición porque con ello se expresa una dimensión constitutiva fundamental de la moderna sociedad capitalista, en la que la esfera de la circulación es lo que se presenta de manera inmediata en la superficie de la sociedad" (223).

A este respecto, en los Grundrisse Marx afirma explícitamente que el proceso de conocimiento de las relaciones sociales capitalistas tiene que comenzar necesariamente con las abstracciones más simples, y a partir de ellas ir generando conceptos progresivamente más concretos con vistas a ir aprehendiendo en el pensamiento lo que aparece inmediatamente como real. Solo si se consuma esta "ascensión" de lo abstracto a lo concreto se comprende el fundamento de lo que aparece inmediatamente (Cf. Grundrisse 1974, 167; 1976, 194). Esta ascensión puede entenderse como una suerte de deducción, ya que "en las formas simples del comienzo están contenidas de manera germinal las formas acabadas, en el sentido de que son momentos abstractos aún no desarrollados teóricamente" (Ruiz SANJuÁn 20i9, 227). Esto es lo que explica para Ruiz Sanjuán que la deducción del concepto de capital tenga lugar a partir del concepto de valor y que una vez deducida lógicamente la categoría del capital, el resto de las categorías se desarrollen a partir de ella, "ya que [el concepto de valor] constituye la categoría central del modo de producción capitalista" (Ibid., 208).

Lo especialmente relevante de estas consideraciones del libro que aquí se presentan es que ellas constituyen las premisas necesarias para comenzar a dar una respuesta a la pregunta acerca de la articulación entre sistema e historia en la crítica de la economía política de Marx. Esta respuesta se despliega en dos pasos. En primer lugar, la entera exposición de la estructura del sistema capitalista avanza deductivamente a partir del concepto de valor hasta alcanzar la categoría del capital en un desarrollo teórico que es independiente del proceso histórico a través del cual ha surgido el capitalismo. Podemos denominar a esta idea la "tesis de la independencia", esto es, de la independencia del despliegue de la exposición sistemática de su génesis histórica. En este sentido, el proceso histórico a través del cual ha surgido el capitalismo queda fuera y es independiente de la exposición sistemática. No obstante, y esto constituye el segundo paso, "la exposición teórica de las relaciones capitalistas constituidas [es] la que da la «clave» para la comprensión del proceso histórico" (Ibid., 217). De 
la exposición sistemática se obtiene, pues, un "principio de orientación" para el estudio de la génesis histórica del capitalismo ya que "el análisis teórico de la estructura acabada indica la dirección en la que hay que investigar los procesos históricos, pero esta investigación histórica, que presupone el desarrollo lógico, tiene a su vez la función de ilustrar la exposición sistemática y, lo que es más importante, de completarla allí donde no es posible la deducción conceptual de los correspondientes fenómenos históricos" (Ibid., 206).

Quisiera mencionar a este respecto cuatro ideas presentes en el texto de Ruiz Sanjuán: la primera, es la relevancia teórica del desarrollo lógico de la exposición del sistema capitalista, puesto que, como hemos visto, el análisis teórico de la estructura acabada indica la dirección en la que hay que investigar los procesos históricos; en segundo lugar, que entre sistema e historia hay a nivel teórico una relación de presuposición: la investigación histórica presupone el desarrollo lógico y sólo entonces obtiene la función de ilustrar la exposición sistemática; en tercer lugar, que la historia completa la explicación de aquello que la exposición sistemática no puede dar cuenta por ella misma y, por último, que el proceso deductivo tiene un "límite insuperable", ya que arriba a ciertos presupuestos históricos de los que no puede dar cuenta.

Esta última cuestión está íntimamente vinculada al procedimiento deductivo que emplea Marx en su exposición del sistema capitalista y que se diferencia del método especulativo hegeliano. La génesis histórica del capitalismo constituye en el proyecto de una crítica de la economía política una suerte de factum del que ha de partir la exposición. "Esto significa que la exposición de Marx, a diferencia de la de Hegel, no cancela sus propios presupuestos, sino que estos determinan, por el contrario, los límites del desarrollo conceptual. Estos supuestos son el producto de un proceso histórico previo, cuyo resultado es la condición objetiva de la exposición del sistema constituido" (Ibid., 242). A pesar de que la comprensión marxiana del método es deudora de la filosofía hegeliana en la medida en que "Marx considera que el método científicamente correcto asciende desde las abstracciones más simples a las determinaciones conceptuales más concretas" (Ibid., 278), Marx no concibe al pensamiento "como un movimiento autosuficiente que no requiera de ningún supuesto exterior a él" (Ibid., 277). Es decir, y esto es muy importante para Ruiz Sanjuán, "la exposición marxiana no suprime en el curso de la misma sus propios presupuestos, como en el caso de la hegeliana, sino que dichos presupuestos permanecen como algo exterior e independiente del proceso lógico" (Ibid., 320), siendo la génesis histórica del capital lo que constituye el propio límite de su análisis sistemático.

Este "límite histórico" se hace patente tras la exposición del sistema, esto es, en los dos últimos apartados del primer volumen de El Capital dedicados a "La llamada acumulación originaria" y "La teoría moderna de la colonización". 
En ellos se ilustra históricamente el surgimiento de la mercancía fuerza de trabajo y del capital dinerario cuya existencia constituye la conditio sine qua non de lo que Marx denomina «relación capitalista». Lo que Marx muestra en estos últimos apartados es que tanto el surgimiento histórico de la mercancía fuerza de trabajo como la acumulación pre-capitalista de dinero son el resultado de procesos históricos que no se pueden deducir de la exposición teórica del propio sistema capitalista. Alcanzar este "límite histórico" tras la exposición del sistema exige, pues, explicar los presupuestos históricos del capitalismo, esto es, "explicar aquello que no resulta accesible a la exposición sistemática de las categorías" (Ibid., 207).

Lo original de la crítica de la economía política de Marx en este punto es que a la necesidad de explicar dichos presupuestos históricos sólo se llega tras la exposición sistemática del modo de producción capitalista. Es decir, "sólo expuesto el sistema capitalista en su configuración esencial, se puede exponer el proceso histórico que ha dado lugar a dicho sistema" (Ibid.). A este respecto, Marx alude a la "circularidad de su exposición" (Cf. Resultate 2009в, 20 y ss; 2000, 109 y ss), pero con ello no se está refiriendo, según Ruiz Sanjuán, "en ningún caso a la circularidad hegeliana, en la que la exposición asume dentro de sí su presupuesto concreto, sino que con ello señala precisamente los límites de [su] exposición" (Ruiz SANJuÁn 20I9, 242); límites que remiten a la constitución histórica de la "relación de capital" que, por cierto, es ella misma "reproducida como resultado del propio proceso de producción" (Ibid., 380) de una manera ampliada.

Estos presupuestos concretos que son analizados al final de los mencionados apartados del primer volumen de El Capital, funcionan desde mi punto de vista como una suerte de "postulados" dentro del desarrollo categorial que presenta Max en El Capital. Ruiz Sanjuán no los interpreta como postulados de la exposición, tampoco lo hace Marx, pero creo que a través de los resultados obtenidos por Ruiz Sanjuán en su trabajo se pueden denominar "postulados" a los presupuestos a los que llega la exposición del sistema capitalista de Marx. Ciertamente, estos presupuestos históricos constituyen el límite exterior de la exposición del sistema, ya que su génesis no se explica ni se puede explicar a través de la exposición del sistema capitalista. Esto conlleva a su vez la apertura de dos ámbitos distintos de investigación: el campo de investigación propio de la crítica de le economía política y el campo de la investigación histórica de los elementos que constituyen los presupuestos fundamentales del sistema de producción capitalista. En este último caso resulta decisivo investigar el surgimiento histórico de la acumulación pre-capitalista de dinero y de los procesos históricos que dieron lugar a la desposesión generalizada de los medios de subsistencia para buena parte de la población, incluyendo en estos últimos, el sur- 
gimiento y establecimiento de las colonias por parte de las potencias coloniales hegemónicas en las distintas fases de la expansión histórica de las relaciones capitalistas de producción.

El otro ámbito de investigación lo constituye la propia crítica de la economía política de Marx: un campo autónomo de investigación y desligado de lo histórico en la medida en que lo que busca presentar El Capital es "la organización interna del modo de producción capitalista, por así decirlo, en su medida ideal" (Kapital 1973, 839; 2009, 1057). Enfatizar la autonomía de ambos campos de investigación es fundamental para disociar la exposición sistemática del sistema capitalista de su génesis histórica, y sobre todo para evitar la interpretación que llevó a Engels a identificar "la deducción conceptual del modo de producción capitalista y la explicación del proceso histórico de formación del mismo" (RUIz SANJUÁn 20 I9, 198). Insistir en dicha autonomía permite poner en tela de juicio esta interpretación de Engels, que en realidad no se corresponde con la comprensión marxiana de la crítica de la economía política ni con la exposición y estructura de El Capital.

Insistimos, a los dos últimos apartados "históricos" del primer volumen de El Capital es preciso arribar, ya que "sólo cuando las categorías que expresan las relaciones del modo de producción capitalista están suficientemente definidas, se puede exponer el proceso histórico a través del cual ha surgido el capitalismo" (Ibid., 198). Este proceso histórico deviene un objeto de estudio fundamental tras la exposición de la estructura social capitalista. Gracias a dicha exposición resulta necesario investigar la génesis histórica de las relaciones capitalistas, la cual a su vez pone de relieve el carácter histórico de dichas relaciones, a pesar de que dicha exposición ya las presupone como plenamente constituidas. Ahora bien, tras la exposición de la estructura social capitalista también se pone de relieve que tanto la existencia de la fuerza de trabajo como la existencia de la posesión inicial de dinero constituyen presupuestos históricos indispensables para el surgimiento de las relaciones de capital. Estos presupuestos tienen que ser postulados por Marx, porque para que sean posibles las relaciones sociales capitalistas ha de haber tenido lugar un proceso histórico de expropiación de los medios de subsistencia de buena parte de la población y ha tenido que acontecer una acumulación pre-capitalista de dinero. Pero, si esto es cierto, resulta inevitable preguntarse si Marx necesita realmente recurrir a la historia para verificar su exposición del sistema capitalista o si puede prescindir de toda corroboración histórica, puesto que ambos fenómenos socio-históricos han tenido que acontecer, ya que de lo contrario no podría explicarse el nacimiento del modo de producción capitalista.

¿Podría influir esta corroboración de los historiadores (que también podría ser una desaprobación a partir de los hechos históricos) en la validez de la 
exposición de las relaciones capitalistas tal y como se presentan en El Capital? Pienso que no, y por este motivo considero oportuno tratar ambos fenómenos históricos (la supuesta expropiación de los trabajadores y la supuesta acumulación pre-capitalista) como dos postulados fundamentales de la crítica de la economía política de Marx. Respecto al primero de estos fenómenos, Marx afirma que la acumulación originaria es indisociable del "proceso histórico de separación de los productores de sus medios de producción" (Kapital I983, 742; 2009, 892), y en Salario, precio y ganancia (I 865) insiste en que "aquello que los economistas denominan acumulación previa u originaria [...] debería de llamarse expropiación originaria. Y veríamos que esta llamada acumulación originaria no es sino una especie de procesos históricos que acabaron destruyendo la unidad originaria que existía entre el hombre trabajador y sus medios de trabajo" (Lohn 1962, 131; i976, 43).

Pienso que la corroboración o desaprobación a partir de los hechos históricos de lo que está aquí diciendo Marx no afecta a la validez de su exposición de las relaciones capitalistas tal y como se presentan en El Capital, porque dichos presupuestos históricos han de ser postulados necesariamente para poder dar cuenta de las relaciones capitalistas plenamente constituidas. En el caso de los trabajadores, por ejemplo, tiene que haberse consumado la separación entre el trabajador y sus medios de subsistencia, porque de lo contrario no se podría encontrar la fuerza de trabajo en el mercado (Cf. Grundrisse i974, 226, 363 y ss; 1976, 260-1, 420 y ss). Los historiadores, en el mejor de los casos, podrán investigar cómo sucedió esta expropiación originaria de los trabajadores, pero no podrán ponerla en duda, ya que se trata con arreglo a lo expuesto en el primer volumen de El Capital de uno de los presupuestos fundamentales sobre el que reposa el sistema de producción capitalista.

En este sentido, Marx insiste también en que el objetivo último que se sigue de la crítica de la economía política es la reinstauración de "la primitiva unidad [de los productores con sus medios de producción] bajo una forma histórica nueva" (Lohn 1962, 131; 1976, 43). De modo que suprimir las relaciones capitalistas equivale a proporcionar de nuevo a los trabajadores sus medios de subsistencia, esto es, a cancelar la mencionada expropiación original (Cf. Kapital I983, 791; 2009, 953). El programa político resultante de la crítica de la economía política resulta, pues, inequívoco: reapropiar a los expropiados suprimiendo la ley de apropiación capitalista. Con ello, dice Marx, "se restaura la propiedad individual, pero sobre el fundamento de la conquista alcanzada por la era capitalista: la cooperación de los trabajadores libres y su propiedad colectiva sobre la tierra y sobre los medios producción producidos por el trabajo mismo" (Ibid.).

En definitiva, el trabajo realizado por Ruiz Sanjuán es una investigación pionera a la hora de dilucidar la relación que mantienen la historia y el sistema 
en la crítica de la economía política de Marx, articulación que sin duda tiene un gran número de aristas. La única cuestión que queda sin tratar explícitamente en su trabajo es lo que yo denominaría el segundo límite exterior del sistema capitalista: el que se vislumbra con su posible supresión. Una de las escasas observaciones que hace Marx al respecto en el primer volumen de $E l C a$ pital es la siguiente: "imaginémonos [...] una asociación de hombres libres que trabajen con medios de producción colectivos y empleen, conscientemente, sus muchas fuerzas de trabajos individuales como una fuerza de trabajo social. [...] [En este caso,] el tiempo de trabajo desempeñaría un doble papel. Su distribución, socialmente planificada, regulará la producción adecuada entre las varias funciones laborales y las diversas necesidades. Por otra parte, el tiempo de trabajo servirá a la vez como medida de la participación individual del productor en el trabajo común, y también, por ende, de la parte individualmente consumible del producto común" (Kapital I983, 92-3; 2009, 96-7). Para mí, resulta de un enorme interés tratar este segundo límite bajo la óptica que nos presenta Ruiz Sanjuán en su libro sobre historia y sistema. Si el primer límite exterior del sistema capitalista apunta a su génesis histórica, el segundo señala hacia su posible trascendencia. El primero de estos límites saca a la luz sus presupuestos históricos, mientras que el segundo nos hace ver que otra sociedad es posible. No obstante, y al igual que el primero, este segundo límite solo se puede obtener tras la exposición del sistema, ya que solo entonces se puede ganar un principio de orientación política con vistas a alterar las relaciones capitalistas de producción. 


\section{REFERENCIAS BIBLIOGRÁFICAS}

Heinrich, M. 2008, Critica de la economía politica. Una introducción a El Capital de Marx, Madrid: Escolar y Mayo.

Heinrich, M. 20 i i, ¿Cómo leer El Capital de Marx? Indicaciones de lectura y comentario del comienzo del Capital, Madrid: Escolar y Mayo.

Marx, K. I962A, Lohn, Preis und Profit, Karl Marx Friedrich Engels Werke (MEW 16), Berlín: Dietz Verlag.

Marx, K. I962B, Kritik des Gothaer Programms, Karl Marx Friedrich Engels Werke (MEW 19), Berlín: Dietz Verlag.

Marx, K 1968, Salario, precio, ganancia, Madrid: Ricardo Aguilera.

Marx, K. I97 I, Critica del Programa de Gotha, Madrid: Ricardo Aguilera.

MarX, K. I974A, Zur Kritik der politischen Ökonomie, Berlín: Dietz Verlag.

MarX, K. I974B, Grundrisse der Kritik der politischen Ókonomie (Rohentwurf) 1857-1858, Berlín: Karl Dietz Verlag.

Marx, K. I976, Elementos fundamentales para la critica de la economía politica, Argentina: Siglo XXI.

Marx, K. I973, Das Kapital. Kritik der politischen Ökonomie, Band III, Karl Marx Friedrich Engels Werke (MEW 25), Berlín: Dietz Verlag.

Marx, K. I983, Das Kapital. Kritik der politischen Ökonomie, Band I, Karl Marx Friedrich Engels Werke (MEW 23), Berlín: Dietz Verlag.

Marx, K I990, Contribución a la critica de la economía política, México: Siglo XXI.

Marx, K. 2000, El Capital. Libro I, Capitulo VI (inédito). Resultados del proceso inmediato de producción, México: Siglo XXI.

Marx, K. 2009A, El Capital, Argentina: Siglo XXI.

Marx, K. 2009B, Resultate des unmittelbaren Produktionsprozesses, Berlín: Karl Dietz Verlag.

Ruiz SANJuÁn, C. 20I4, "La evolución teórica del marxismo: del materialismo histórico a la crítica de la conciencia fetichista", Isegoría. Revista de Filosofía Moral y Politica, 50: 143-65.

Ruiz Sanjuán, C. 2019, Historia y sistema en Marx. Hacia una teoría critica del capitalismo, Madrid: Siglo XXI. 
